\title{
Emotional burnout of teachers in the context of the transition to distance learning
}

\author{
Nelli Khachaturyan* \\ Don State Technical University, 344000, Rostov-on-Don, Russia
}

\begin{abstract}
The article discusses the problem of emotional burnout of teachers when switching to distance learning, in connection with the spread of the COVID-2019 epidemic and the introduction of quarantine. Research methods: 1. Methods for the diagnosis of professional burnout of $\mathrm{K}$. Maslach, S. Jackson in the adaptation of N.Ye. Vodopyanova. 2. Diagnostics of emotional burnout of personality by V.V. Boyko. The reliability of the research results is ensured by the methodological validity of the sought positions, the use of methods adequate to the purpose, object and subject of the work, as well as the use of methods of mathematical data processing: the Mann-Whitney U-criterion. The results obtained in the course of the study make it possible to assert that for teachers such drastic changes became significant stress due to a sharp change in the usual teaching system and an urgent need for the operational development of new skills that did not previously affect their professional suitability, which entailed additional psychological load, a state of active tension, a reduction in professional duties, which led to emotional exhaustion, which intensified the symptoms of emotional burnout. Thus, we can conclude that after the transition to distance learning, teachers show a more pronounced level of emotional burnout arising from the influence of factors associated with professional activity, which contribute to personality deformation and the further development of emotional burnout. A training program and practical recommendations were prepared for the prevention of emotional burnout of teachers
\end{abstract}

\section{Introduction}

The introduction of quarantine in educational institutions, in connection with the COVID2019 pandemic and the need for a sharp transition to online education, was the biggest shock for the education system. In the context of the changes currently taking place in the field of education, such drastic changes have become a significant stress for teachers due to the complete collapse of the usual teaching system and high requirements for the quality of their professional training.

The definition of burnout syndrome was first introduced by the American psychologist H.J. Freudenberg in 1974 to characterize the psychological state of healthy people who are in close and intense communication with clients in an emotionally depressed atmosphere while providing professional assistance. In this article, we will adhere to the theory of Boyko

${ }^{*}$ Corresponding author: nellja-nik@mail.ru 
V.V., in which emotional burnout is considered as a personality-developed mechanism of psychological defense in the form of complete or partial exclusion of emotions in response to traumatic influences, manifested as a state of physical and mental exhaustion caused by emotional overstrain, which decreases due to the formation of a personal stereotype of professional behavior. Professional burnout is understood a stress syndrome as a set of symptoms that negatively affect performance, well-being, relationships in the process of professional activity of the subjects of this activity. Despite the fact that in modern conditions of pedagogical activity the urgency of the problem of emotional and professional burnout is obvious, the study of this phenomenon has a long tradition. From the middle of the last century to the present, quite a lot of works have appeared that lie within the framework of the analysis of the concept of emotional burnout syndrome (Bradley; 1969; Freudenberger; 1974), the presentation of models for studying this phenomenon (Maslach, Jackson, 1986; Pines and Aaronson, 1988; Dierendonck, Schaufeli, Sixma 1994); studying burnout syndrome outside of professional activity (Kendall, 2018; Mikolajczak, 2018). Of scientific interest is the study of the relationship between psychological health and imbalance between work and personal life (Guest, 2002) and the relationship between perfectionism and burnout syndrome (Larskikh, 2010). Our research is based on the three-component concept of K. Maslach and S. Jackson (Maslach, Jackson, 1981), who distinguish three components in the burnout syndrome, including the study of emotional exhaustion, depersonalization and reduction of professional success. Also, there is confirmation of the correlation between the structure of professional and emotional burnout with such psychological factors as motivational expectations and personality traits, age and work experience $[1,2]$.

In Russian psychology V.V. Boyko viewed burnout as a psychological defense mechanism. V.E. Orel, N.V. Grishina argues that the state of burnout is closely related to the loss of a sense of the meaning of activity as one of the components of the meaning of life, the devaluation of professional achievements and, in especially severe cases, can cause existential neurosis. N.E. Vodopyanova notes that the causes of professional burnout can be excessive involvement, dependence, workaholism [3]. According to the European Conference of the World Health Organization, about a third of specialists in socionomic professions, including educators, suffer from "professional stress" and annually turn to psychologists and doctors with problems related to professional burnout and professional efficiency. There is a correlation between stress and coping tasks and ongoing burnout and self-efficacy. The results of this study confirm the continued use of selected stress and coping criteria for teacher well-being, and discuss areas for further research and potential use of these indicators $[4,5]$.

Considering the individual differences in the attitude of teachers to a sharp transition to online learning, in connection with the motives underlying professional activities, an interesting study was carried out, the results of which showed that the positive perception of teachers of the unexpected transition to online learning and the prospects for the development of their own competencies is positive related to the objectives of the learning approach. Whereas, the goals of avoiding work were accompanied by the perception of this change as threatening, which, in turn, is positively associated with burnout levels and negatively associated with assessments of the quality of teaching by students [6]. It should be noted that the attitude of university students to distance learning under conditions of uncertainty was also studied [7]. Research examining the metrics of academic adaptation and re-coding coping strategies confirms that multiple coping behaviors predict academic performance and functioning, especially outcomes that are meaningful in terms of motivation. Process research has suggested several ways in which overcoming difficulties can contribute to academic success: by encouraging persistence, by mitigating the impact of personal or interpersonal resources, and by protecting student performance from academic risks [8]. 
In connection with the problems under consideration, the results of the study of emotional characteristics and styles of pedagogical communication [9], the study of the relationship of representatives of different generations in the educational environment [10], the analysis of students' ideas about the socio-psychological qualities of teachers [11], the influence of the emotional background and a favorable mood not only for the socio-psychological climate, but also for interpersonal relationships in the family structure [12], as well as the study of the relationship between the relationship of children with parents and teachers in primary school with involvement and motivation in high school, as well as the reaction of parents and teachers to competence and skills of preparing children for school are of great importance[13,14]. Given the fact that interaction with students' parents is a necessary component of effective professional communication, teachers with signs of emotional burnout may avoid communication. A number of researchers emphasize the importance of supportive relationships between staff and parents and view these relationships as a resource one. Studying how social bonds between parents and employees develop and change, the authors found that a selected group of parents develops and activates strong social bonds with employees for resources and support. The development of strong ties reflects the special social process of building interaction and the experience of mutual understanding, at crucial moments when employees demonstrate reliability [15]. In the practice of psychological support for professional health, it is effective to use the resource approach at different stages of the professional path [16].

In order to minimize burnout, it is important to maintain physical and psychological health, emotional stability, a high level of professionalism and social activity, systematically improve skills and personal effectiveness [17], to meet the educational needs of teachers, in connection with the need to switch to distance education and the use of digital technologies in teaching, it is necessary to increase the media information literacy of teachers [18]. Pedagogical activity is a special type of activity, which, in terms of psychological overload, is one of the most difficult types of work, involving high service, selfless devotion to the profession and to other people, application by a professional of all his intellectual, physical and moral forces. A high level of responsibility for the result of their work before students, parents, administration and society, special requirements for the resource capabilities of teachers: flexibility, mobility, tolerance, stress resistance, quick adaptation to dramatically changing conditions, the ability to work in multitasking mode and emotional stress potentially contain the danger of emotional and professional burnout.

\section{Materials and methods}

The purpose of this study was to study the emotional burnout of teachers in the context of the transition to distance learning. The hypothesis of the study was the assumption that the transition to distance learning in a pandemic contributes to the emotional burnout of teachers.

Research methods: 1. Methods for the diagnosis of professional burnout of K. Maslach, S. Jackson in the adaptation of N.Ye. Vodopyanova. 2. Diagnostics of emotional burnout of personality by V.V. Boyko.

The reliability of the research results is ensured by the methodological validity of the sought positions, the use of methods adequate to the purpose, object and subject of the work, as well as the use of methods of mathematical data processing: the Mann-Whitney Ucriterion. Data processing was carried out using the SPSS 20.0 for Windows computer program.

Empirical object of research: the teaching staff of the municipal budgetary educational institution in the amount of 35 people, including 30 women and 5 men aged from 27 to 65 years with higher education. All survey participants were informed about the goals, objectives and progress of the study, based on the results of which a program was developed: 
"The syndrome of emotional burnout of a teacher: prevention and overcoming" and practical recommendations for the prevention of this syndrome were offered.

\section{Results}

On the basis of the school, a study of the syndrome of emotional burnout of teachers was carried out, which took place in two stages (the first - before the transition to distance learning, the second after the transition to the standard form of education) and confirmed the relevance of the study of this problem among teachers.

The first stage of the study was carried out from 10.03.2020 to 20.03.2020. The results obtained for the indicators of emotional burnout according to the method of V.V. Boyko for a group of teachers are presented in Table 1.

Table 1. Indicators of the degree of emotional burnout for a group of teachers, obtained according to the results of the study before the transition to distance learning

\begin{tabular}{|l|c|c|c|}
\hline & $\begin{array}{c}\text { Phase } \\
\text { not formed }\end{array}$ & $\begin{array}{c}\text { Phase in the stage of } \\
\text { formation }\end{array}$ & Formed phase \\
\hline Tension & 13 & 5 & 17 \\
\hline Resistance & 23 & 4 & 8 \\
\hline Depletion & 29 & 5 & 1 \\
\hline
\end{tabular}

The data obtained indicate that in the surveyed group, the greatest number of teachers developed a phase of "stress" (49\% of respondents) with a pronounced symptom of "experiencing traumatic circumstances", which means that teachers are currently experiencing the influence of traumatic factors, stress is increasing, which leads to despair and resentment. The insolubility of the situation leads to the development of "burnout" phenomena. The feeling of "dissatisfaction with oneself" was formed in a very small number of teachers $(5 \%)$, which suggests that, in general, teachers do not feel dissatisfied with themselves in the profession and with specific circumstances in the workplace.

At the same time, in the course of the study, it was revealed that in the group of subjects there are formed symptoms of emotional burnout, such as "symptom of inadequate selective emotional response" and "symptom of expanding the sphere of economy of emotions", and this form of protection is carried out outside the professional field - in communication with family and friends. The presence of these symptoms indicates the formation of the "resistance" phase.

The "Depletion" phase in the surveyed group of teachers as a whole is not formed, however, there is a respondent whose results indicate the formation of the "emotional deficit" symptom, which manifests itself in the feeling of his inability to help the subjects of their activity emotionally.

The results of the study carried out in the period from 20.05.2020 to 01.06.2020, presented in Table 2, reflect the psychological state of teachers after the transition to distance learning.

Table 2. Indicators of the degree of emotional burnout for a group of teachers, obtained according to the results of the study after switching to distance learning

\begin{tabular}{|l|c|c|c|}
\hline & $\begin{array}{c}\text { Phase } \\
\text { not formed }\end{array}$ & $\begin{array}{c}\text { Phase in the stage of } \\
\text { formation }\end{array}$ & Formed phase \\
\hline Tension & 9 & 6 & 20 \\
\hline Resistance & 15 & 8 & 12 \\
\hline Depletion & 25 & 7 & 3 \\
\hline
\end{tabular}


The indicators presented in Table 2 indicate a sharp increase in the number of respondents who have formed the phase of "resistance" (growth by $50 \%$ ).

In the group of subjects, there is a significant predominance of the "symptom of inadequate selective emotional response", expressed in behavior according to the principle "I want it or I don't want it": I think it is necessary - I will pay attention to the student, there will be a mood - I will respond to his condition and needs. Despite the unacceptability of this style of emotional behavior, it is very common.

The next in severity is the symptom of "reduction of professional responsibilities", which has developed among $25 \%$ of teachers, manifested in attempts to facilitate or reduce responsibilities that require emotional costs.

At the same time, in the group, the percentage of teachers with the prevailing symptom of "caged" in the "stress" phase increased. This means that these people feel or begin to feel a state of intellectual and emotional congestion, a dead end.

In addition, the existing changes in the form of education led to the formation of the symptom of "anxiety and depression", which developed in a significant number of teachers $(22.5 \%)$, this indicates that these people experience stress in the form of experiencing situational and personal anxiety, disappointment in the profession. The prevailing symptom of nervous anxiety means the beginning of resistance to stressful situations and the beginning of the formation of emotional protection.

In the phase of "depletion" the symptom of "personal detachment" began to dominate; it developed in $27.5 \%$ of teachers. This symptom manifests itself in a partial loss of interest in the subject of professional activity. For clarity, the results are presented graphically in Figure.

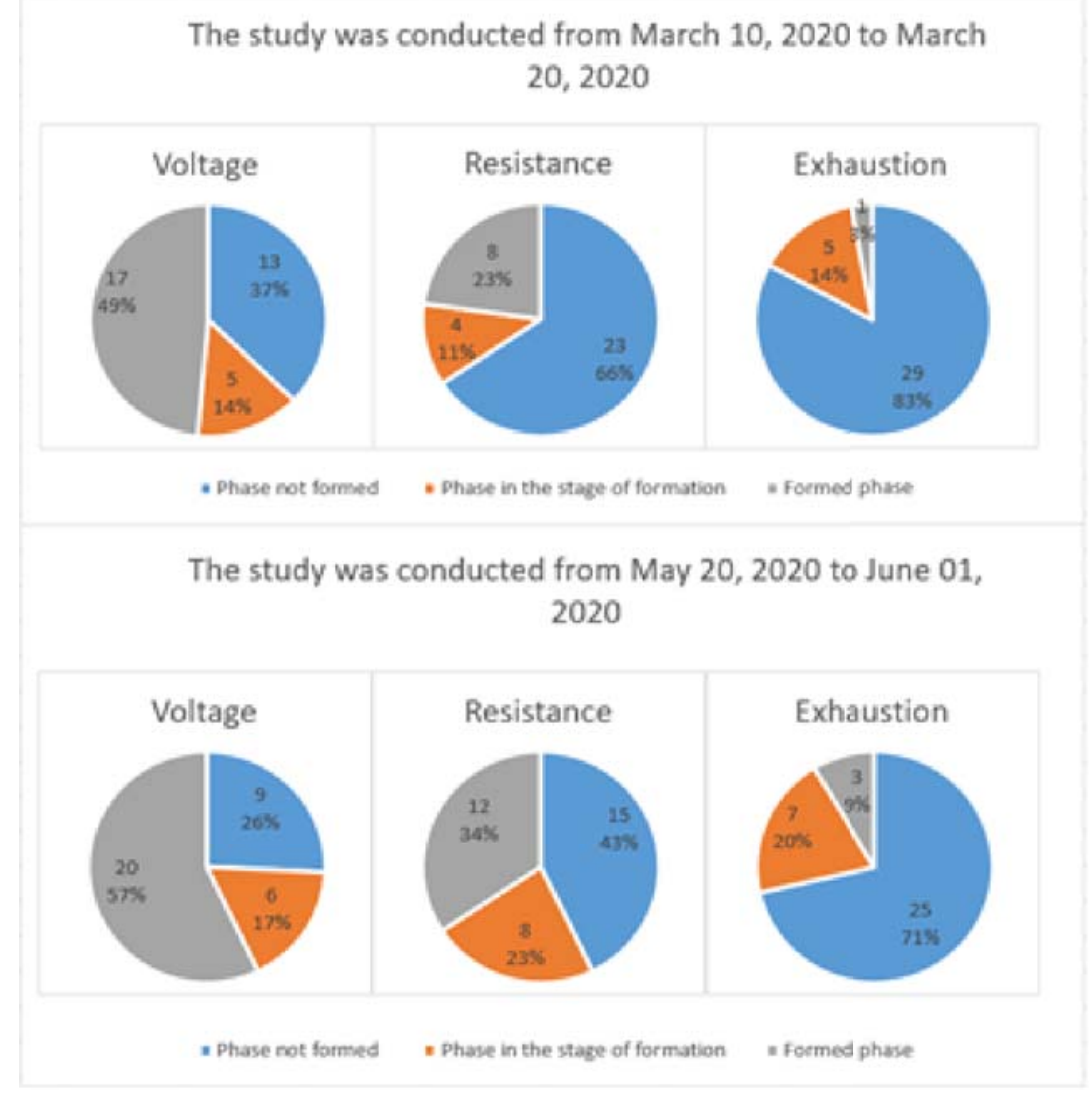

Fig. 1. Results of the study of the level of emotional burnout of teachers 
In order to identify the degree of professional burnout and its various aspects in teachers, we used the method of diagnosing professional burnout by K. Maslach and S. Jackson modified by N.E. Vodopyanova, E.S. Starchenkova.

The results of professional burnout indicators obtained during the study in the traditional form of education are presented in Table 3, the results obtained during the transition to distance learning are presented in Table 4.

Table 3. Indicators of the degree of professional burnout for a group of teachers, obtained during the research according to the method of $\mathrm{K}$. Maslach, before the transition to distance learning

\begin{tabular}{|c|c|c|c|}
\hline & $\begin{array}{c}\text { Phase } \\
\text { not formed }\end{array}$ & $\begin{array}{c}\text { Phase in the stage of } \\
\text { formation }\end{array}$ & Formed phase \\
\hline $\begin{array}{c}\text { Emotional } \\
\text { exhaustion }\end{array}$ & 14 & 6 & 15 \\
\hline Depersonalization & 13 & 14 & 8 \\
\hline $\begin{array}{c}\text { Reduction of } \\
\text { personal } \\
\text { achievements }\end{array}$ & 22 & 4 & 9 \\
\hline
\end{tabular}

Table 4. Indicators of the degree of professional burnout for a group of teachers, obtained during the research according to the method of $\mathrm{K}$. Maslach, after switching to distance learning

\begin{tabular}{|c|c|c|c|}
\hline & $\begin{array}{c}\text { Phase } \\
\text { not formed }\end{array}$ & $\begin{array}{c}\text { Phase in the stage } \\
\text { of formation }\end{array}$ & Formed phase \\
\hline $\begin{array}{c}\text { Emotional } \\
\text { exhaustion }\end{array}$ & 9 & 7 & 19 \\
\hline Depersonalization & 13 & 13 & 9 \\
\hline $\begin{array}{c}\text { Reduction of } \\
\text { personal } \\
\text { achievements }\end{array}$ & 13 & 8 & 14 \\
\hline
\end{tabular}

Analyzing the results obtained, we see that according to the scale of "Emotional exhaustion", the surveyed group during the distance learning period obtained results corresponding to a high level of symptom development ( $43 \%$ of respondents had a phase formed, $17 \%$ - in the stage of formation), if we compare this indicator with the indicator for the traditional form of education, it can be seen that the severity of this symptom among teachers did not increase significantly, $27 \%$ and $17 \%$, respectively.

On the scale "Depersonalization", high results were also obtained, for about $40 \%$ of teachers this phase was formed, however, a change in the form of teaching did not have a significant effect on this symptom. "Depersonalization" is characterized by a disorder of selfperception, one's own actions are perceived as if from the outside and are accompanied by a feeling of impossibility to control them.

The greatest growth in the period of distance learning is expressed on the scale "Reduction of personal achievements". During the second testing, the surveyed teachers showed the results corresponding to a high level of development of this symptom, exceeding the initial ones by $50 \%$. For clarity, the results are presented graphically in Figure. 


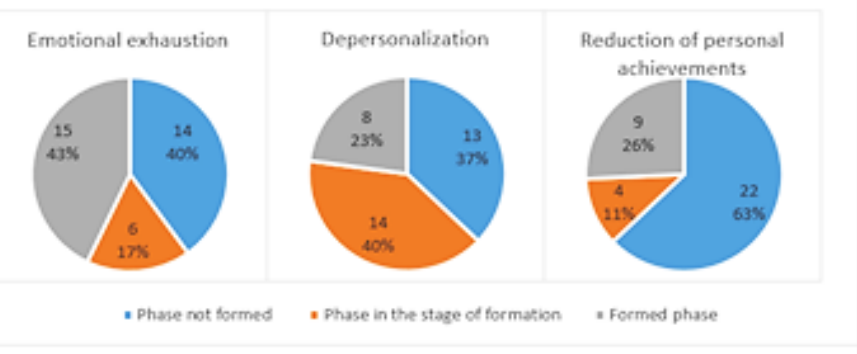

The study was conducted from May 20, 2020 to June 01, 2020

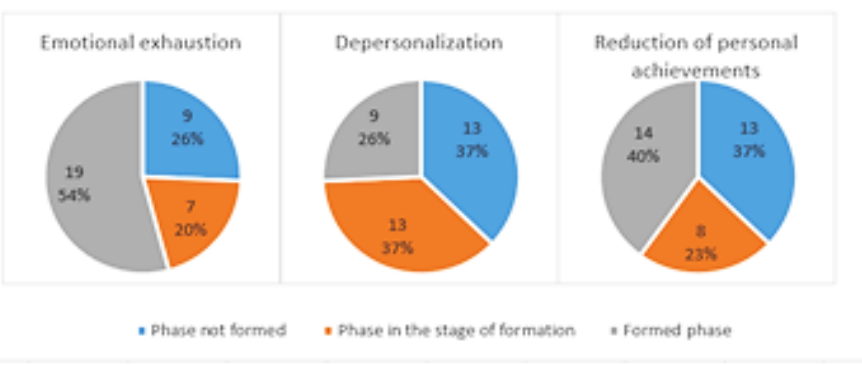

Fig. 2. The results of studying professional burnout among teachers in the context of the transition to distance learning

\section{Discussion}

The results obtained in the course of the study allow us to assert that the transition to distance learning led to the formation of the third stage of emotional burnout in a greater number of teachers in the phase of "tension" and in the phase of "resistance". In the "depletion" phase, $70 \%$ of the subjects are not subject to burnout syndrome. This fact may indicate that, despite the psychological imbalance formed among teachers against the background of distance learning, when carrying out certain correctional work, a greater number of teachers can cope with the negative manifestations of the emotional burnout syndrome.

Comparing the indicators of professional burnout, we can conclude that the highest percentage of burnout, which was also influenced by a change in the form of education, according to the third scale "reduction of personal achievements", which manifests itself in a tendency to negatively assess oneself, one's professional achievements and advantages and opportunities. On the scales "Emotional exhaustion" and "Depersonalization" there are also high rates of burnout, however, the studied effect of changing the form of education is not significant.

To identify the significance of the differences, the data were statistically processed using the Mann-Whitney U-test. Null hypothesis $\mathrm{H} 0=$ the level of the feature in the second sample is not lower than the level of the feature in the first sample\}; alternative hypothesis - H1 = \{the level of the feature in the second sample is lower than the level of the feature in the first sample\}. Based on the results of the study, according to the formula (1), the Mann-Whitney U-criterion was calculated, the value $U=38.5$ was obtained; according to the Mann-Whitney table, the critical point $\operatorname{Ucr}(0.05)=45$ was found, since $\operatorname{Ucr}(\alpha) \geq U$, the differences in sample levels can be considered significant. 
Thus, we can conclude that after the transition to distance learning, teachers show a more pronounced level of emotional burnout, which arises as a result of the influence of factors associated with professional activity, which contribute to personality deformation and the further development of emotional burnout.

\section{Conclusion}

During the period of distance learning, teachers were faced with the task of quickly mastering new skills that did not previously affect their professional suitability, which entailed additional psychological stress, a state of active tension, a reduction in professional duties, which led to emotional exhaustion, which intensified the symptoms of emotional and professional burnout, manifested in a tendency towards a negative assessment of oneself, one's professional achievements and successes, negativism regarding service merits and capabilities.

Thus, the proposed assumption that the transition to distance learning in a pandemic contributes to the emotional burnout of teachers has been confirmed. All research tasks have been completed, the research goal has been achieved.

This study is of practical importance, since its results can be used in solving problems related to the prevention of emotional and professional burnout of teachers.

\section{References}

1. V.E. Orel, Psychological journal 22 (1), 90-101 (2008). https://psyjournal.ru/articles/fenomen-vygoraniya-v-zarubezhnoy-psihologiiempiricheskie-issledovaniya.

2. N.E. Vodopyanova, E.S. Starchenkova, Burnout syndrome: diagnosis and prevention (Peter, SPb, 2013). https://psychojournal.ru/books/2169-vodopjanova-n-estarchenkova-e-s-sindrom-vygoranija-diagnostika-i-profilaktika.html.

3. G.S. Nikiforov, N.E. Vodopyanova, E.A. Rodionova, Z.F. Dudchenko, Psychological factors of professional burnout, Grow up: International scientific-practical congress of pedagogues, psychologists and medics, Geneva (Switzerland), 30 November 2016. European Association of pedagogues and psychologists "Science". - Geneva (Switzerland). 74-79 (2016) https://elibrary.ru/item.asp?id=28109496.

4. M.C. Pérez-Fuentes, J.J. Gázquez-Linares, M.M. Molero-Jurado, Á. Martos-Martinez, A.B. Barragán-Martín, M.M. Simón-Márquez, International Journal of Clinical and Health Psychology 21(2), (2021). doi.org/10.1016/j.ijchp.2021.100225.

5. C.L. Eddy, K.C. Herman, W.M. Reinke, Concurrent and predictive validity and sensitivity to change Journal of School Psychology 76, 17-32 (2019). doi.org/10.1016/j.jsp.2019.05.001.

6. M. Daumiller, R. Rinas, J. Hein,S. Janke, O. Dickhäuser, Computers in Human Behavior 118, (2021). doi.org/10.1016/j.chb.2020.106677.

7. I. Abakumova, G. Zvezdina, A. Grishina, E. Zvezdina, E. Dyakova, E3S Web of Conferences 210, 18017 (2020). doi.org/10.1051/e3sconf/202021018017.

8. E.A. Skinner, E.A. Saxton, Developmental Review 53, (2019). doi.org/10.1016/j.dr.2019.100870.

9. A. Belousova, G. Kozhukhar, Emotional characteristics and styles of pedagogical communication of educators, INTED2018 Proceedings (12th International Technology, Education and Development Conference), 0291-0298 (2018) doi: 0.21125/inted.2018. 
10. V. Pishchik, A. Belousova, L. Ryumshina, The Relationship of Generations Representatives in the Educational Environment, EDULEARN18 Proceedings (10th International Conference on Education and New Learning Technologies), Palma, Spain, 1782-1786 (2018). doi: 10.21125/edulearn.2018.

11. A. Korochentseva, E. Suroedova, N. Khachaturyan, O. Nikolenko, SHS Web of Conferences 70, 08020 (2019). doi.org/10.1051/shsconf/20197008020.

12. J. Kreneva, E. Suroedova, O. Korzhova, T.Ozerova, E3S Web of Conferences. (2020) doi.org/10.1051/e3sconf/202021019015.

13. Castle HeatlyM., E. Votruba-Drzal, Journal of Applied Developmental Psychology 60, 144-156 (2019). doi.org/10.1016/j.appdev.2018.09.003.

14. L. McLean, N. Sparapani, C.C. McDonald, S. Day, Contemporary Educational Psychology 61, (2020). doi.org/10.1016/j.cedpsych.2020.101863.

15. C.Barnes, S.Nolan, Children and Youth Services Review 98, 238-251(2019) doi.org/10.1016/j.childyouth.2019.01.004.

16. N.E. Vodopyanova, G.S. Nikiforov, S.M. Shingaev, E.A. Stolyarchuk, Application of the resource approach in the practice of psychological support of professional health, Labor subject and organizational environment: problems of interaction in the context of globalization, Tver State University, 124-139

(2019) https://elibrary.ru/item.asp?id=41202376.

17. John Frank, M.D. Ninivaggi, Chapter 6 - Physician Wellness: Engaging Mindfulness Learned Mindfulness Physician Engagement and M.D. 113-135 (2020). doi.org/10.1016/B978-0-12-816484-6.00006-3.

18. B. Novković Cvetković, L. Stošić, A. Belousova, Croatian Journal of Education 20 (4), 1089-1114 (2018). doi.org/10.15516/cje.v20i4.3001. 